\section{Usos de orações existenciais em teses de doutorado}

Uses of existential clauses in doctoral thesis conclusions

Cícera Alves Agostinho de SÁ (UERN) ciceralvesdsa@gmail.com

João Bosco FIGUEIREDO-GOMES (UERN) boscofigueiredo@gmail.com

Recebido em: 31 de out. de 2019. Aceito em: 05 de maio de 2020.
SÁ, Cícera Alves Agostinho de; FIGUEIREDO-GOMES, João Bosco. Usos de orações existenciais em teses de doutorado. Entrepalavras, Fortaleza, v. 10, n. esp., p. 101-119, ago. 2020. DOI: $10.22168 / 2237-6321-$ gesp1770.

Resumo: Este trabalho objetiva analisar a utilização dos processos existenciais na escrita acadêmica com foco em realizações que ocorrem na unidade retórica Conclusão, no banco de dados TACTESE, organizado por FigueiredoGomes e Bertuleza (no prelo). Os processos existenciais representam o que existe ou acontece (HALLIDAY; MATTHIESSEN, 2004, 2014). A metodologia empregada consiste no recenseamento das ocorrências dos processos existenciais, utilizando a ferramenta Concord, do suíte computacional Word Smith Tools (SCOTT, 2018). O levantamento de dados é realizado com base na lista de processos tipificados por Halliday e Matthiessen (2004, 2014), e aplicados a usos da língua inglesa, como neutros, abstratos e com traços circunstanciais, os quais Fuzer e Cabral (2014) apresentam como passíveis de realizações com sentido existencial em língua portuguesa. Os resultados apontam que os processos mais produtivos são os tipificados como neutros, a exemplo de haver, existir, ter, ocorrer e acontecer; os processos com nível de ocorrência intermediário seriam encontrar-se e resultar, tipificados como processos com traços circunstanciais; os processos tipificados como abstratos 
v. 10 (esp)

101-119

ago.

2020

não foram identificados no banco de dados analisado. Acredita-se que essa ausência pode-se relacionar ao nível de tecnicidade do texto tese de doutorado, pois ele parece não admitir realizações de processos abstratos, mais previsíveis em gêneros do narrar.

Palavras-chave: Processsos existenciais. Conclusão. Tese de doutorado.

Abstract: This paper aims to analyse the use of existencial processes in academic writing with focus on achievements that occur in the Conclusion rhetorical unit, in the TACTESE database, organized by Figueiredo-Gomes and Bertuleza, in press. Existential processes represent what exists or happens. (HALLIDAY; MATTHIESSEN, 2004, 2014). The methodology used consists in a occurrences census of existential processes, using the Concord tool, from the Word Smith Tools computational suite (SCOTT, 2018). The data collection is carried out based on the processes list typified by Halliday and Matthiessen (2004, 2014) as neutral, with circumstantial and abstract features in English uses, which Fuzer and Cabral (2014) present in portuguese language achievements existential realizations. The results indicate that the most productive processes are those typified as neutral, such as (there) be (haver), exist (existir), have (ter), occur (ocorrer) and happen (acontecer); processes with an intermediate level of occurrence are lie (encontrar-se) and result (resultar), typified as processes with circumstantial features; and no occurrences of abstract processes are identified in Conclusions of doctoral theses. By way of conclusion, it is believed that such absence may be related to the level of technicality of the doctoral thesis text, since it doesn't seem to admit realizations of abstract processes, which would be more predictable in narrative genres.

Keywords: Existential processes. Conclusion. Doctoral thesis.

Introdução

No escopo da tradição gramatical, a transitividade é abordada como um fenômeno restrito aos verbos e seus complementos, enquanto para a Gramática Sistêmico-Funcional (GSF), a transitividade constitui um sistema que possibilita a descrição da oração, com base em seus componentes: processos, participantes e eventuais circunstâncias.

Para a GSF, a oração é compreendida como uma unidade de análise. Do grupo de componentes, os processos são considerados pela teoria como a categoria central da oração. Eles se encontram organizados em principais e secundários. Os principais compreendem experiências humanas, a saber: materiais, mentais e relacionais; os secundários se situam nas fronteiras destes, respectivamente, classificando-se como: verbais, comportamentais e existenciais.

O último processo apresentado no grupo dos secundários é, certamente, o que apresenta menor número de ocorrências em corpora investigados, com base na proposição de Halliday e Matthiessen (2004; 2014), segundo os quais as orações existenciais restringem-se a entre 3 e 4 por cento de todas as orações em textos da língua inglesa. Um dos elementos que caracterizam as orações existenciais é a admissão restrita de um único participante, o Existente. 
Em língua portuguesa, as ocorrências de oração existencial em textos acadêmicos podem ainda ser mais investigadas, à luz da Linguística Sistêmico-Funcional (LSF), pois os processos existenciais foramidentificados em um número reduzido de trabalhos, dentre os quais elencamos: uma breve seção na obra de Fuzer e Cabral (2014), em que as autoras apresentam o estudo mais teórico sobre os processos existenciais na Língua Portuguesa, segundo a GSF; a dissertação de Oliveira (2014), que trata das orações existenciais em inglês e português brasileiro; a dissertação de Lima (2013), que estuda os processos existenciais em reportagem de capas de revistas; o trabalho de Lima-Lopes (2001), que inclui os processos existenciais no estudo de cartas de vendas; e o trabalho de Morais (2015), que discute o uso do processo existencial haver na escrita acadêmica. Deste grupo, apenas o último trabalho trata da ocorrência do processo existencial haver em artigos científicos e discute seus usos nesse tipo de escrita.

Diante disso, o objetivo deste trabalho consiste em analisar a utilização dos processos existenciais neutros, com traços circunstanciais e abstratos na escrita acadêmica da unidade retórica Conclusão, com base na descrição dos usos mais frequentes e nos diferentes significados identificados nesse contexto.

Para tanto, utilizamos amostras do banco de dados Texto Acadêmico Tese de Doutorado - TACTESE, organizado por FigueiredoGomes e Bertuleza, que se encontra no prelo, e adotamos a Linguística de Corpus como orientação metodológica para o recenseamento e tabulação dos dados. Utilizamos a ferramenta Concord, do suíte computacional Word Smith Tools - WST (SCOTT, 2018) para realizar o levantamento das orações com processos existenciais, que servirão para a análise contextual das ocorrências e dos elementos linguísticos que constituem o entorno desses processos.

O artigo está organizado da seguinte maneira: primeiramente, apresentamos a GSF como a teoria que abaliza a investigação, dando destaque à Metafunção Ideacional, que abriga o Sistema de Transitividade. Com base nesse sistema, discorremos sobre a construção da experiência na configuração da oração pelos componentes: processos, participantes e circunstâncias. Especificamos, logo após, as orações existenciais. Na sequência, apresentamos a metodologia, que se vale da Linguística de Corpus e das ferramentas do suíte computacional WST, que são aplicadas na análise dos usos dos processos existenciais na unidade retórica Conclusão de tese de doutorado em Língua Portuguesa. Por fim, nas Considerações Finais realizamos o fechamento dos achados até então nesse estudo piloto em relação aos usos dos processos existenciais na escrita acadêmica, segundo a GSF. 
v. 10 (esp)

101-119

ago.

2020

\section{A Gramática Sistêmico-Funcional}

O funcionalismo linguístico abriga várias vertentes (Funcionalismo Norte-americano, Linguística Sistêmico-Funcional, Gramática Funcional do Discurso, Sociofuncionalismo, Linguística Funcional Centrada no Uso), que têm em comum o estudo da linguagem em uso.

A LSF trata da perspectiva social da linguagem, que é compreendida como um sistema de significados construídos socialmente, com base na interação. O fato de a linguagem ser cultural advém de essa constituir-se com base na realidade. Esse conjunto de fatores contribui para que a linguagem seja analisada situada em um contexto sociocultural.

A Gramática Sistêmico-Funcional, por sua vez, associa-se à LSF. Para a LSF, a língua resulta do contexto, sendo a linguagem em uso seu foco. São as relações sociais que motivam os usos analisados, com base em categorias da GSF. A teoria aponta que as escolhas léxicogramaticais são condicionadas pelo contexto, de modo que os fatores situacionais são adotados como referência à definição dos aspectos a serem investigados.

O termo contexto é importante porque demarca conceituações da GSF, ao tratar de macro e microestruturas. Halliday (1978) situa a linguagem no Contexto de Situação e no Contexto de Cultura.

Segundo a concepção do autor, o Contexto de Cultura compreende o plano macroestrutural da língua, constituído pelos significados externos ao texto. Esse contexto pode ser definido como um sistema semiótico, que constitui a linguagem, sendo também por ela constituído. Trata-se do conjunto de valores e normas de determinada comunidade, cujos membros são responsáveis pela constituição da cultura, que se apresenta como basilar a esse contexto.

O Contexto de Situação contempla o plano microestrutural da língua, sendo constituído pelas variáveis: Campo, Relação e Modo. O Campo remete à natureza das atividades semióticas e sociais que se processam entre os usuários da língua, resultando em situações comunicativas; a Relação decorre do papel assumido por cada participante nesse processo interativo, bem como os valores por eles negociados; o Modo, por sua vez, diz respeito ao meio como os interlocutores utilizam a linguagem. 
De acordo com Halliday e Matthiessen (2014), o Contexto de Situação consiste em "uma representação abstrata do ambiente em termos de determinadas categorias gerais que têm relevância para o texto" (HALLIDAY; MATTHIESSEN, 2014, p. 375). A estrutura desse contexto é constituída por sistemas semióticos, que favorecem a análise do uso funcional da linguagem, com base no campo, nas relações e no modo do discurso.

Cientes de que função e necessidade são construções culturais, compreende-se que a linguagem serve a determinadas funções enquanto satisfaz às diferentes necessidades. A inter-relação entre linguagem e cultura se constitui em decorrência do caráter funcional da linguagem. Desse modo, linguagem e cultura são inseparáveis, visto que uma se encontra imbricada na outra.

As variáveis Campo, Relação e Modo, consideradas basilares ao Contexto de Situação, dão origem às metafunções, categorias fundamentais da GSF, que serão discutidas na seção seguinte.

As metafunções da linguagem

As metafunções são decorrentes de componentes funcionais, situados no plano semântico-discursivo, o qual é responsável pela organização funcional da linguagem. Ratificamos, com base em Halliday e Matthiessen (2004, 2014), que as orações são consideradas a unidade basilar às análises agasalhadas na GSF, embora elas se situem em textos que servem como contexto às análises.

Halliday e Matthiessen (2004, 2014) explicam o termo metafunção dissociando-o da noção clássica de função, explorada com evidência no plano das funções da linguagem, cuja abordagem se restringe ao objetivo ou meio onde ocorre seu uso.

De acordo com Fuzer e Cabral (2014), as metafunções compreendem manifestações dos propósitos implícitos aos usos da língua. Para cada variável apresentada no Contexto de Situação, decorre uma metafunção da linguagem, a saber: da variável de contexto Campo procede a Metafunção Ideacional; das Relações, deriva a Metafunção Interpessoal; ao Modo, associa-se a Metafunção Textual.

A Metafunção Textual é considerada como o elemento facilitador da organização do texto, seja falado ou escrito. No cerne dessa metafunção, os componentes da oração são analisados com base nos definidores Tema e Rema, sendo que o primeiro apresenta sempre valor 
v. 10 (esp)

101-119

ago.

2020

ideacional e apresenta-se como o assunto principal da oração enquanto mensagem, configurando-se como o responsável pela apresentação ou retomada do conteúdo; o Rema apresenta ou desenvolve as informações presentes no Tema.

O mundo social serve como plano de realização à Metafunção Interpessoal, que considera a linguagem como processo de interação, realizada por meio das relações sociais e interpessoais. As categorias que se agasalham nessa metafunção possibilitam o exame do sistema de MODO, que trata das escolhas entre os modos oracionais declarativo, interrogativo ou imperativo.

A Metafunção Ideacional da linguagem constitui um sistema semântico de representação do mundo. É o componente ideacional que auxilia a construção da nossa experiência do mundo, tanto interior como exterior. Essa metafunção abriga a Transitividade, sistema de relações entre componentes, cujos elementos centrais são os processos principais (materiais, mentais e relacionais) e secundários (verbais, comportamentais e existenciais). Interessa-nos, para a presente pesquisa, os processos existenciais. Para abalizá-los, dedicamos, mais especificamente, a seção seguinte à apresentação da Metafunção Ideacional.

\section{Metafunção Ideacional e Transitividade}

Segundo Halliday e Matthiessen (2014, p. 48), a Metafunção Ideacional esclarece de que modo os "fenômenos de nossa experiência são construídos como categorias e relações de significado". Integra essa metafunção o conjunto de significados ideacionais, relativos à representação dos acontecimentos do mundo, sendo que esses assumem um caráter especial, distintos um do outro, diferenciação baseada no modo como a linguagem é codificada no quadro mental.

A Metafunção Ideacional abriga o desejo de transformar a expressão da realidade em significados, estando associada à habilidade dos sistemas semióticos utilizados na representação de objetos e suas relações com o mundo.

Para Halliday e Matthiessen (2004, 2014), a base ideacional seria organizada como uma rede de sistemas que se encontram interrelacionados por fenômenos. Esses fenômenos podem ser definidos como uma categoria experiencial mais geral, representando a experiência humana. 
No nível da oração, a gramática e a semântica se desenvolvem concomitantemente, expressando, de modo experiencial, segundo Halliday e Matthiessen (2014, p. 169), "um quantum de mudança como uma figura ou configuração de um processo, participantes nele envolvidos e quaisquer circunstâncias relacionadas".

As categorias semânticas de análise envolvidas na Metafunção Ideacional, utilizadas na configuração de um processo experiencial, configuram-se por meio dos componentes obrigatórios: processos e participante(s), além das circunstâncias, que podem eventualmente ocorrer ou não. No entanto, há uma dependência sintagmática e paradigmática entre os elementos que constituem os sistemas presentes na oração, sendo os participantes realizados por grupos nominais, os processos por grupos verbais e as circunstâncias por grupos adverbiais ou sintagmas preposicionais.

Para Halliday e Matthiessen (2014, p. 170), o sistema de transitividade "constrói o mundo da experiência em um conjunto de tipos de processos". Esses processos se encontram organizados em duas categorias: básicos e secundários, que serão detalhadas na sequência.

Componentes das orações: categorias para análises funcionais

Como já afirmamos, o Sistema de Transitividade fundamenta atividades de análises sistêmico-funcionais, que se processam com base nos componentes da oração, a saber: processos, participantes e circunstâncias. Desse conjunto, processo e participante se apresentam como obrigatórios, sendo que as circunstâncias são eventuais e ocorrem, livremente, referindo-se às condições e coerções relacionadas ao processo.

Halliday e Matthiessen (2004, 2014) consideram os processos como centrais para a Transitividade. Os processos podem expressar experiências internas, relacionadas aos estados afetivos e cognitivos; também podem expressar experiências externas, concernentes às ações e aos eventos. Assim, a oração se apresenta como uma representação da realidade, sempre construída a partir de um tipo de processo da experiência humana.

A disposição e classificação dos processos em principais e secundários, já apresentados, é consequência do fato de os principais apresentarem uma recorrência maior no discurso de modo geral, e de os secundários se encontrarem situados nas fronteiras, intercalando os 
v. 10 (esp)

101-119

ago.

2020

principais. Os participantes, por sua vez, são definidos em decorrência das funções desempenhadas mediante cada processo. Na sequência, apresentamos os processos e participantes categorizados pela GSF.

Os Processos Mentais estão relacionados à representação dos acontecimentos que ocorrem no mundo interior, e encontram-se divididos nos subtipos: cognitivos, que se encontram relacionados ao pensamento e à compreensão; perceptivos, que consistem na observação de fenômenos; afetivos, que remetem aos sentimentos; e desiderativos, que se relacionam à expressão dos desejos. Os participantes dos Processos Mentais são o Experienciador e o Fenômeno. Na mente do primeiro participante, o processo se realiza, enquanto o Fenômeno constitui o elemento percebido ou sentido pelo Experienciador.

Os Processos Materiais se relacionam às ações do mundo físico. Seus participantes principais são o Ator e a Meta, sendo que o primeiro participante realiza a ação e tem presença obrigatória; já a Meta constitui o participante para quem se dirige o processo.

Os Processos Relacionais, também definidos como processos de ser, relacionam duas entidades presentes na oração. Halliday (1994) aponta três possibilidades de realização desses processos: intensivo, circunstancial ou classificativo. Cada tipo pode ser ainda classificado como atributivo, que relaciona o participante Portador e Atributo, ou como identificativo, cujos participantes denominam-se Identificado e Identificador.

No limiar dos processos básicos, situam-se os processos secundários. Esses processos são definidos por Halliday e Matthiessen (2004, 2014) em comportamentais, verbais e existenciais.

Os Processos Comportamentais são constituídos por ações que remetem aos comportamentos físicos ou psicológicos, que ocorrem de modo simultâneo. Esses processos, a exemplo dos processos mentais, exigem a ocorrência de um participante personificado ou animado. Nesse processo, o participante definido como Comportante realiza a ação, enquanto o Behavior (Comportamento) define o escopo do processo.

Os Processos Verbais se situam entre os processos mentais e relacionais e encontram-se associados aos processos de dizer, que se realizam também no campo simbólico, já que o Dizente pode ou não ser humano. Os participantes desses processos são constituídos pelos Dizentes, que realizam a ação; pelo Receptor, para quem a mensagem é enviada; pelo Alvo, que constitui a entidade atingida pelo processo; e pela Verbiagem, que consiste naquilo que foi expresso ou significado pelo Dizente. 
O Processo Existencial está situado entre os processos relacionais e materiais, realizando-se, prototipicamente, pelos verbos haver, existir e ter, podendo ainda ter seus significados realizados por uma lista considerável de processos, que serão detalhados a posteriori. Esse processo apresenta um único participante: o Existente.

Os elementos circunstanciais, segundo Halliday (1994), podem ser identificados nas ocorrências de todos os tipos de processos, acompanhadospelos participantesapresentados. Esseselementos serealizam pela ocorrência de advérbios, locuções adverbiais e grupos preposicionados, introduzindo informações complementares ao significado do processo.

As circunstâncias constituem o terceiro elemento da oração e estão relacionadas às condições e coerções em que se realizam cada processo. Os elementos circunstanciais mais recorrentes, conforme Halliday e Matthiessen (2004, 2014) seriam: de extensão e de localização, que se desdobram em temporal e espacial; de modo, que apresentam as variáveis: maneira, meio, qualidade e comparação; de papel, que constrói a significação de ser ou tornar-se; de acompanhamento, que apresenta significado comitativo ou aditivo; de causa, que se desdobra em razão, propósito ou benefício; de contingência, que remete à condição ou concessão; de ângulo, que pode ser de fonte ou ponto de vista; e, por fim, de assunto, que equivale circunstancialmente à verbiagem.

$\mathrm{Na}$ sequência, tratamos dos componentes das orações existenciais, que constituem o objeto de estudo desta pesquisa.

\section{As Orações Existenciais}

As Orações Existenciais foram eleitas como objeto de investigação do presente trabalho, cuja discussão se fundamenta na GSF. Para Halliday e Matthiessen (2014, p. 307), essas orações "representam que algo existe ou acontece". Embora as orações existenciais ocorram em pequeno número caso comparadas aos demais cinco tipos descritos, exercem papel importante em diversos tipos de textos.

Para Fuzer e Cabral (2014, p. 79) "O verbo típico da oração existencial é "haver" (em sentido de existir)." (grifo das autoras) Em realizações existenciais com o processo haver, em língua inglesa, identificase sempre a presença do elemento there, situado antes da flexão do processo be, embora esse elemento não desempenhe função experiencial. As funções desse elemento estão associadas às metafunções interpessoal e textual. Em língua portuguesa não há representação desse elemento. 
v. 10 (esp)

101-119

ago.

2020

Ainda de acordo com Fuzer e Cabral (2014, p. 79) "Em português (assim como no espanhol) a oração existencial não apresenta sujeito." Deste modo, o participante existente não pode ser categorizado como sujeito, em decorrência da ausência do traço de agentividade. O participante Existente pode representar pessoa, objeto, abstração, instituição ou evento.

Os grupos verbais que dão origem aos Processos Existenciais, apresentados por Fuzer e Cabral (2014), adaptados de Halliday e Matthiessen (2004, 2014) estão organizados nos tipos neutros, com traços circunstanciais e abstratos, conforme se encontra apresentado no Quadro 1:

Quadro 1 - Processos Existenciais em Língua Portuguesa, segundo Fuzer e Cabral

\begin{tabular}{|l|l|l|}
\hline \multicolumn{2}{|c|}{ Tipos } & \multicolumn{1}{c|}{ Verbos } \\
\hline \multirow{2}{*}{ Neutros } & Existir & existir, perdurar, restar, sobreviver \\
\cline { 2 - 3 } & Acontecer & surgir, acontecer, ocorrer, ter (lugar), suceder \\
\hline $\begin{array}{l}\text { Com traços } \\
\text { circunstanciais }\end{array}$ & Tempo & suceder, resultar, seguir-se \\
\cline { 2 - 3 } & Lugar & $\begin{array}{l}\text { situar-se, localizar-se, encontrar-se, estar } \\
\text { (suspenso), surgir, emergir, crescer }\end{array}$ \\
\hline Abstratos & & irromper, florescer, vigorar \\
\hline \multicolumn{2}{|l|}{ Fonte: Fuzer e Cabral (2014, p. 96, adaptado de HALLIDAY; MATTHIESSEN, 2004). }
\end{tabular}

Os processos apresentados como neutros se relacionam semanticamente aos significados de existir ou acontecer. Conforme ocorre com o processo (there) be, do inglês, os processos existir e acontecer também se flexionam na língua portuguesa a depender do Existente, único participante, que funciona sintaticamente como sujeito inativo. Diante dessa constatação, compreendemos que o tipo neutro (neutral), apresentado por Halliday e Matthiessen (2004, 2014) para denominar Processos Existenciais que se situam no grupo semântico do exist e happen em língua inglesa, tem equivalentes em língua portuguesa existir (haver) e acontecer - com o mesmo comportamento.

Os processos existenciais que apresentam traços circunstanciais assumem o significado de situar temporalmente, ou localizar geograficamente o participante que o complementa. Nesses casos, a localização ou indicação temporal é realizada pelo processo, não ficando restrita às circunstâncias, que se realizam por meio de grupos preposicionais ou adverbiais.

Os processos que apresentam sentido existencial "abstrato" (abstract) se situam no grupo semântico que sugere incoação, incepção, por meio dos processos irromper (que significa surgir), florescer (que pode significar desenvolver, passar a existir), vigorar (que significa entrar em vigor). 
Com base na descrição da tipificação dos processos existenciais em neutros, com traços circunstanciais e abstratos, procuramos analisar seus usos na escrita acadêmica, em Conclusões de teses de doutorado. A seguir, detalhamos passos metodológicos seguidos neste trabalho.

\section{Metodologia}

Com base em Halliday e Matthiessen (2004, 2014), acerca da língua inglesa, e em Fuzer e Cabral (2014), acerca da língua portuguesa, tratamos das orações existenciais em situações de uso, com base em categorias do Sistema de Transitividade, no escopo da GSF.

Esse trabalho é um recorte da tese de doutoramento, denominada provisoriamente: Usos dos processos existenciais em tese de doutorado de língua portuguesa: uma abordagem sistêmicofuncional ${ }^{1}$, que trata dos usos e das funções desses processos em orações existenciais, recenseadas no banco de dados TACTESE, por unidade retórica e por grande área do conhecimento.

Neste trabalho analisamos os usos e as funções desempenhadas pelos componentes das orações existenciais, na unidade retórica Conclusão, do banco de dados TACTESE. Escolhemos esses processos para analisar sua frequência e os significados decorrentes de seus usos em figuras de existir, em razão de sua importância na construção de enunciados em que o agente não é identificado.

A opção pelo gênero de texto tese de doutorado se justifica em razão de nos permitir analisar em que medida os significados decorrentes da tipificação apresentada por Halliday e Matthiessen (2004; 2014) dos processos existenciais em neutros, com traços existenciais e abstratos, associadas aos gêneros do narrar, se processa nesse gênero de texto.

Já a escolha da unidade retórica Conclusão, que pode ser também denominada Considerações Finais, se deu em razão de o tipo de linguagem utilizada pelo pesquisador na elaboração dessa unidade atender ao propósito não de comunicar verdades, mas de elaborar uma interpretação, em que o agente pode ou não ser informado. Logo, o recenseamento e análise dos dados indicam em que medida os processos existenciais, considerados como o elemento nuclear na configuração de orações existenciais, foi explorado nessa unidade retórica.

\footnotetext{
${ }^{1}$ Tese de doutoramento vinculada ao Programa de Pós-Graduação em Letras - PPGL, da Universidade do Estado do Rio Grande do Norte - UERN, sob a orientação do professor Doutor João Bosco Figueiredo Gomes - UERN.
} 
v. 10 (esp)

101-119

ago.

2020

O recenseamento das ocorrências dos processos existenciais para este trabalho é realizado apenas na unidade retórica Conclusão, das 24 teses de doutorado, de diferentes áreas do conhecimento, que constituem o banco de dados TACTESE, organizado por FigueiredoGomes e Bertuleza (no prelo), também em razão de a discussão das demais unidades retóricas desse gênero de texto atender a um dos objetivos específicos da tese de doutoramento à qual esse trabalho se filia.

Sob a orientação da Linguística de Corpus, utilizamos a ferramenta Concord, do suíte computacional Word Smith Tools (SCOTT, 2018), para o recenseamento e tabulação dos dados. Para a coleta das ocorrências dos processos, observamos se os usos dos processos apresentavam ou não a significação existencial, com base na categorização dos processos passíveis de realizar esses significados.

O recenseamento dos processos existenciais nas conclusões das teses de doutorado se deu considerando os processos listados por Halliday e Matthiessen (2004; 2014) na adaptação dos equivalentes do inglês para a Língua Portuguesa, realizada por Fuzer e Cabral (2014, p. 96), conforme o Quadro 1. Acrescentamos os processos haver e ter, ambos significando existir, usados como existenciais na Língua Portuguesa.

Na sequência, apresentamos a análise qualitativa, com base no levantamento quantitativo, das ocorrências dos processos em orações existenciais presentes no banco de dados.

\section{Os processos existenciais nas Conclusões de Teses de Doutorado}

O levantamento quantitativo das ocorrências de realizações de processos com significados existenciais na unidade retórica Conclusão, do banco de dados TACTESE, aponta para resultados presentes no Gráfico 1. 
Gráfico 1 - Processos tipificados como neutros com sentido existencial
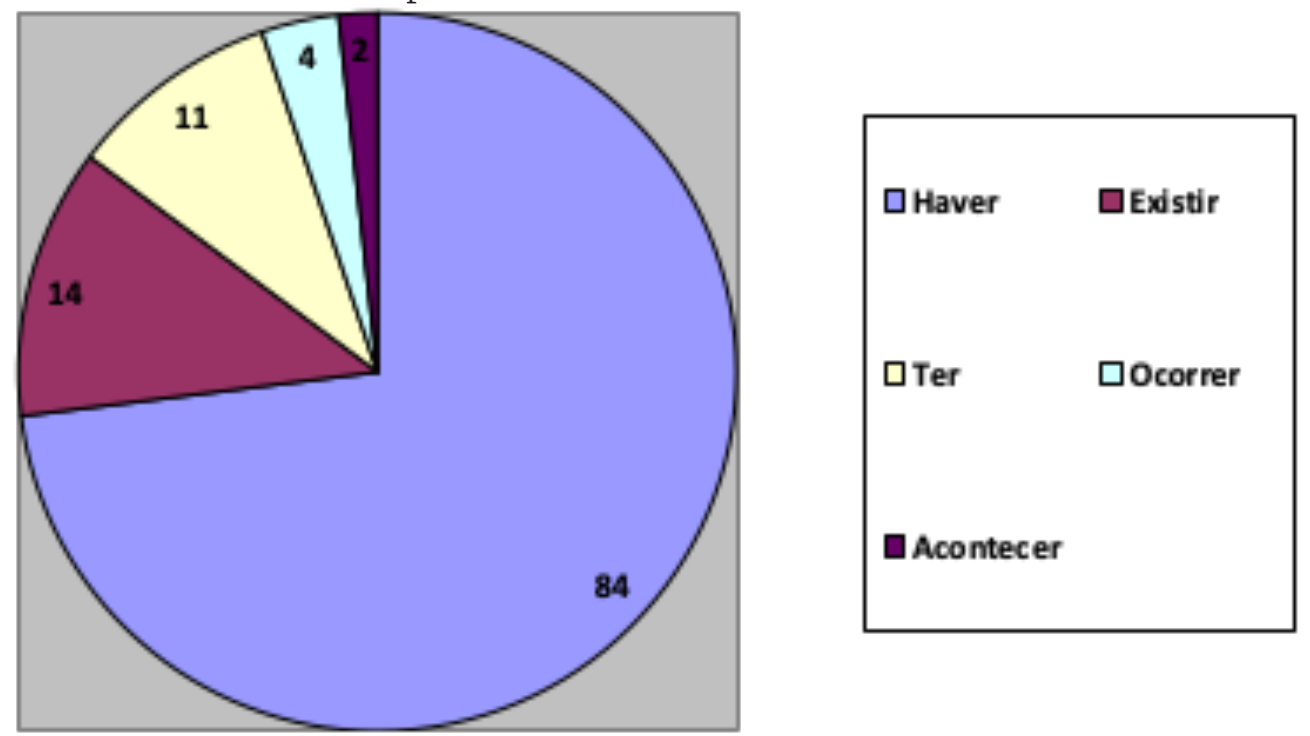

Fonte: Elaborado pelos autores.

Conforme o Gráfico 1, que desenha a distribuição dos 115 usos dos processos existenciais tipificados na literatura como neutros, podemos apresentar as seguintes considerações. O Processo Existencial haver (= existir) foi o que apresentou o maior número de ocorrências, com 84 (73\%) realizações. Os demais usos encontrados foram em uma escala decrescente de ocorrências: existir, com 14 (12\%); ter, com 11 $(9,6 \%)$; ocorrer, 4 (3,5\%); e acontecer, com 2 (1,7\%).

Esses dados, relativos ao texto acadêmico, já modificariam o Quadro 1, pois teria, na primeira subdivisão, os processos haver/ existir, identificados no banco de dados TACTESE, como representantes dos processos existenciais tipificados na literatura como neutros, que agregaria os demais processos com sentido de existir. Deste modo, os processos existenciais neutros do subtipo existir, passariam a ser identificados pelo subtipo haver/existir, descritos com base na listagem de Fuzer e Cabral (2014) e nos usos verificados no banco de dados em análise, podendo ser assim enumerados: haver, existir, perdurar, restar e sobreviver.

Esse reordenamento pode ser justificado em razão de o processo haver ser considerado por Halliday e Matthiessen (2004; 2014) como existencial prototípico e não ter sido incluso na lista de processos que podem realizar significados existenciais, do tipo neutro, do subtipo existir, que passa a ser haver/existir. Já o lugar que o processo haver ocupa na enumeração dos processos existenciais neutros desse subtipo pode ser justificado em razão de a frequência identificada no banco 
v. 10 (esp)

101-119

ago.

2020

de dados em análise ser convergente com a afirmação de Halliday e Matthiessen (2004, 2014) e Fuzer e Cabral (2014), de que esse lideraria a frequência dos processos que realizam significados existenciais em língua inglesa e em língua portuguesa.

Com base também no critério de frequência, na segunda subdivisão dos processos existenciais do tipo neutro, em vez do grupo do "acontecer", viria o processo ter, cujo significado fica na fronteira da existência e do possessivo. Nesse caso, o processo ter, apresentado pela GSF como relacional possessivo se configura ainda como o elemento central na configuração de figuras de existir, podendo ser categorizado como existencial possessivo.

Abrir-se-ia uma terceira subdivisão para o grupo do acontecer. Desse modo, os processos existenciais neutros do subtipo acontecer ficariam assim enumerados: acontecer, ter, surgir, ocorrer e suceder. Desse subtipo, os processos identificados foram acontecer e ter, que realizam significados neutros do acontecer. As razões pelas quais o processo ter constituiria a segunda divisão e também estaria representado na terceira subdivisão estão justificadas na análise das amostras, situadas após os quadros 2 e 3.

No Quadro 2, apresentamos amostras de orações coletadas das unidades retóricas Conclusão, do banco de dados TACTESE, que realiza significado existencial, centrando-se em processos categorizados como existenciais, e admitindo apenas a presença do participante Existente.

Quadro 2 - Amostras de ocorrências dos processos existenciais com significado neutro extraídas do banco de dados TACTESE

\begin{tabular}{|l|l|l|}
\hline$(1)$ & $\begin{array}{l}\text { "[...] havia } \\
\text { (Processo Existencial) }\end{array}$ & $\begin{array}{l}\text { um incipiente e frágil } \\
\text { compromisso [...]." } \\
\text { (Participante: Existente) }\end{array}$ \\
\hline$(2)$ & $\begin{array}{l}\text { "Existe } \\
\text { (Processo Existencial) }\end{array}$ & $\begin{array}{l}\text { mais de uma concepção de Estado } \\
\text { [..]" } \\
\text { (Participante: Existente) }\end{array}$ \\
\hline $\begin{array}{l}\text { (3) "Também } \\
\text { (Circunstância: de }\end{array}$ & $\begin{array}{l}\text { Teve } \\
\text { (Processo Existencial) }\end{array}$ & $\begin{array}{l}\text { um significado híbrido." } \\
\text { (Participante: Existente) }\end{array}$ \\
\hline
\end{tabular}

Fonte: Elaborado pelos autores.

Nas amostras do Quadro 2, o Processo Existencial realizado pelos componentes "havia", "Existe" e "teve" são representados pelo participante Existente (algo que existe), confirmando o elemento caracterizador desse tipo de processo, apontado por Halliday e Matthiessen (2004, 2014). O Existente pode ser pessoa, objeto, 
fenômeno, lugar, instituição, abstração, ação ou evento. À direita dos processos vem o participante, introduzindo uma informação nova, considerada como construção apresentativa ou introdutória. Além da posição de Rema, há a presença do determinante indefinido. De acordo com a GSF, esse aspecto organizacional da oração tem influência nas análises realizadas com base na Metafunção Textual, para que o Tema constitui a parte inicial da oração como mensagem e o Rema é tudo que se apresenta a seguir do Tema.

Uma particularidade do Processo Existencial ter, em textos do gênero acadêmico, especialmente em teses de doutorado ora em estudo, é o fato de, diferentemente de (3) do Quadro 2, a oração existencial apresentar dois participantes como propomos analisar no Quadro 3.

Quadro 3 - Amostras de ocorrências do ter como processo existencial com significado neutro extraídas do banco de dados TACTESE

\begin{tabular}{|c|c|c|c|}
\hline $\begin{array}{l}\text { "Desse modo } \\
\text { (Circunstância } \\
\text { de Modo) }\end{array}$ & $\begin{array}{c}\text { (nós) } \\
\text { (Participante: } \\
\text { Possuidor }\end{array}$ & $\begin{array}{c}\text { temos } \\
\text { (Processo } \\
\text { Existencial } \\
\text { Possessivo) } \\
\end{array}$ & $\begin{array}{l}\text { as evocações para elementos } \\
\text { técnicos:" } \\
\text { (Participante: Existente } \\
\text { Possuído) }\end{array}$ \\
\hline $\begin{array}{l}\text { "Na somatória } \\
\text { de toda a } \\
\text { escolaridade } \\
\text { (Circunstância } \\
\text { de Extensão de } \\
\text { duração) }\end{array}$ & $\begin{array}{c}\text { (nós) } \\
\text { (Participante: } \\
\text { Possuidor) }\end{array}$ & $\begin{array}{c}\text { temos } \\
\text { Processo } \\
\text { Existencial } \\
\text { Possessivo) }\end{array}$ & $\begin{array}{l}\text { os } 9 \text { anos de Ensino } \\
\text { Fundamental" } \\
\text { (Participante: Existente } \\
\text { Possuído) }\end{array}$ \\
\hline $\begin{array}{l}\text { "Nos congressos } \\
\text { e publicações } \\
\text { (Circunstância } \\
\text { de Localização }\end{array}$ & $\begin{array}{c}\text { (nós) } \\
\text { (Participante: } \\
\text { Possuidor }\end{array}$ & $\begin{array}{l}\text { temos } \\
\text { (Processo } \\
\text { Existencial } \\
\text { Possessivo) }\end{array}$ & $\begin{array}{l}\text { a pretensão de divulgar a } \\
\text { abordagem Sociológica e } \\
\text { Comunicacional do Discurso } \\
\text { (Participante: Existente } \\
\text { Possuído) }\end{array}$ \\
\hline
\end{tabular}

Fonte: Elaborado pelos autores

Com base no Quadro 3, defendemos que as amostras se fundem ou estão na fronteira entre existencial e relacional. O Processo Existencial "temos" assume o significado de "ter existência" e o escrevente do texto assume a posse (Possuidor), por meio do plural majestático (de modéstia) de ter, do Existente Possuído, que também pode ser pessoa, objeto, fenômeno, lugar, instituição, abstração, ação ou evento.

Cabe destacarmos que essa nossa visão difere dos existenciais de um participante caracterizado na literatura da LSF e da tradição gramatical, mas nos apoiamos nas fronteiras com os processos principais, defendidos pela LSF, no caso de o ter Existencial fundirse com o fronteiriço Processo Relacional, que se realiza com dois participantes. 
v. 10 (esp)

101-119

ago.

2020

Acerca dos processos existenciais tipificados no grupo "com traços circunstanciais", o levantamento quantitativo aponta para o seguinte resultado: do processo encontrar-se foram identificadas três ocorrências, das quais duas se encontram no Quadro 4 para análise. O processo resultar apresenta duas ocorrências, dentre as quais selecionamos uma para análise, conforme podemos ver no Quadro 4.

Quadro 4 - Amostras de ocorrências dos processos existenciais com traços circunstanciais extraídas do banco de dados TACTESE

\begin{tabular}{|c|c|c|c|}
\hline \multicolumn{2}{|c|}{$\begin{array}{l}\text { (1) A seguir, na Tabela } 5.7 \\
\text { (Circunstância de Localização - Lugar) }\end{array}$} & $\begin{array}{l}\text { encontra-se } \\
\text { (Processo } \\
\text { Existencial) }\end{array}$ & $\begin{array}{l}\text { a transcrição das } \\
\text { respostas. } \\
\text { (Participante: } \\
\text { Existente) }\end{array}$ \\
\hline \multicolumn{2}{|c|}{$\begin{array}{l}\text { (2) A matriz do trabalho } \\
\text { (Participante: Existente) }\end{array}$} & $\begin{array}{l}\text { encontra-se } \\
\text { (Processo } \\
\text { Existencial) } \\
\end{array}$ & $\begin{array}{l}\text { no final do trabalho, [...] } \\
\text { (Circunstância de } \\
\text { Localização - Lugar) }\end{array}$ \\
\hline $\begin{array}{l}\text { (3) Dessa } \\
\text { convivência, } \\
\text { (Circunstância de } \\
\text { Causa - Razão) }\end{array}$ & $\begin{array}{l}\text { [quando se quer } \\
\text { harmoniosa], } \\
\text { (Circunstância } \\
\text { de tempo } \\
\text { contigencial) }\end{array}$ & $\begin{array}{l}\text { resulta } \\
\text { (Processo } \\
\text { Existencial) }\end{array}$ & $\begin{array}{l}\text { a junção de saberes } \\
\text { [...] } \\
\text { (Participante: } \\
\text { Existente) }\end{array}$ \\
\hline
\end{tabular}

As orações (1) e (2) do Quadro 4 corroboram a realização do Processo Existencial "encontra-se" com as circunstâncias de lugar, conforme a proposta apresentada no Quadro 1. Temos de atentar, ainda, para o significado decorrente dessa oração, e de outros usos que tratam não de um lugar físico, mas funciona como um componente que situa o participante dentro do próprio texto acadêmico, funcionando como um recurso metadiscursivo, em que o termo é adotado em uma perspectiva autoexplicativa/autodefinitiva. Esse uso parece peculiar aos gêneros acadêmicos, por ser bastante produtivo. Por isso, sugerimos, também, incluir uso metadiscursivo, ampliando a proposição de Halliday e Matthiessen (2004; 2014), restrita, por enquanto, aos traços circunstanciais que se processam apenas no meio físico.

Na amostra (3) do Quadro 4, o Processo Existencial "resulta" atua com o participante Existente "a junção de saberes". A oração existencial apresenta o traço circunstancial de tempo "quando se quer harmoniosa", conforme apresentado no Quadro 1, a partir de Fuzer e Cabral (2014, p. 96, adaptado de Halliday e Matthiessen, 2004), embora o traço também signifique o tempo da condição (contingência). Há também a circunstância "Dessa convivência". Embora a GSF não sugira 
a tipificação de traços circunstanciais de Causa, o significado decorrente do uso aponta para essa interpretação. Fica, então, a sugestão do aditivo dessa tipificação aos elementos circunstanciais.

Não foram identificadas ocorrências dos processos tipificados como abstratos na unidade retórica Conclusão do corpus analisado. Acreditamos que a ausência de processos existenciais tipificados como abstratos nessa unidade retórica pode se encontrar relacionada ao nível de tecnicidade do gênero de texto tese de doutorado, posto que esse pode não admitir realizações desse tipo de processo, que seria mais previsível em gêneros do narrar.

Trouxemos ao debate alguns usos dos Processos Existenciais da Língua Portuguesa na unidade retórica Conclusão, do banco de dados TACTESE. Na sequência apresentamos as considerações finais a este trabalho.

\section{Considerações finais}

Os resultados apontam que os processos com sentido existencial identificados no banco de dados, tipificados como neutros, são 'haver', 'existir', 'ter', 'ocorrer' e 'acontecer'. O levantamento quantitativo mostra que o processo haver é o que apresenta maior número de ocorrências também na unidade retórica Conclusão das teses de doutorado que constituem o banco de dados TACTESE, confirmando a indicação de Halliday e Matthiessen (2004, 2014), de que esse seria o processo existencial mais produtivo.

Com base nesses dados, a categorização dos processos existenciais neutros, tipificados como existir e acontecer poderia ter as seguintes alterações: a primeira divisão, presente no Quadro 1, deixaria de ser apenas existir, passando a comportar também o haver, resultando no haver/existir; a segunda possível alteração na divisão do Quadro 1, adaptado por Fuzer e Cabral (2014, p. 80), seria a substituição da categorização acontecer por ter. Isso se deve ao fato de identificarmos um novo uso do processo ter, situado nas fronteiras entre o existencial e o relacional. Nesses casos em que o ter realiza dois participantes, o Processo Existencial assume o significado de ter existência, por meio do qual o escrevente do texto usa o nós elíptico como Participante Possuidor do Participante Existente Possuído. Em relação aos "neutros", seria, ainda, criada uma terceira divisão que comportaria o grupo do acontecer. 
v. 10 (esp)

101-119

ago.

2020

Ao que nos parece, a tipificação dos Processos Existenciais em neutros, trazida por Halliday e Matthiessen (2004, 2014), não explicaria os significados construídos por meio dos usos desses processos na unidade retórica Conclusão, em teses de doutorado do banco de dados TACTESE, no qual as construções se aproximariam do prototípico ou mesmo genuíno significado existencial.

Conforme a análise de ocorrências do Processo Existencial com traços circunstanciais encontrar-se no corpus, observamos que elas se realizam com significados não de um lugar físico, conforme acontece em textos narrativos, mas funcionam como recurso metadiscursivo autoexplicativo ou autodefinitivo. Esse uso pode ser característico do texto acadêmico, mas poderia ser agregado, ampliando, para a Língua Portuguesa, a proposição de Halliday e Matthiessen (2004, 2014), cujas amostras se situam em textos do narrar.

Ainda situadas no grupo das realizações dos processos com traços circunstanciais, foram identificadas duas ocorrências do processo resultar com significado existencial. Esse uso sugere uma tipificação do processo existencial com traços circunstanciais de causa, que não foi catalogada por Halliday e Matthiessen $(2004,2014)$ e, relação à Língua Inglesa, apresentando-se como uma ampliação das contribuições da GSF.

Não identificamos ocorrências dos processos tipificados como abstratos na unidade retórica Conclusão do banco de dados analisado. Acreditamos que a ausência desses processos existenciais na unidade retórica Conclusão pode se encontrar relacionada ao nível de tecnicidade do texto acadêmico tese de doutorado, dado que eles seriam mais previsíveis em gêneros do narrar.

Diante disso, podemos afirmar que tanto a LSF (GSF), quanto a Linguística de Corpus foram de grande valia para os nossos achados e as nossas discussões.

Pesquisas posteriores podem explorar o nível de ocorrências e o processo de construção de significados de orações existenciais em outras unidades retóricas do gênero de texto teses de doutorado, visto que a presente pesquisa se deteve apenas no levantamento e na análise de amostras de ocorrências nas Conclusões do banco de dados TACTESE.

Esse estudo evidencia que a construção de significados em uma perspectiva sistêmico-funcional decorre das funções desempenhadas pelos componentes nas orações, que se situam em textos, realizados em situações de interação, caracterizando a linguagem em uso, foco de investigação das pesquisas baseadas na Gramática Sistêmico-Funcional. 


\section{Referências}

FIGUEIREDO-GOMES, J. B; BERTUlEZA, C. D. S. Banco de dados TACTESE. Açu/RN: UERN, no prelo.

FUZER, C.; CABRAL, S. R. S. Introdução à gramática sistêmico-funcional em língua portuguesa. Campinas - São Paulo: Mercado de Letras, 2014.

HALLIDAY. M. A. K. A linguagem como semiótica social: a interpretação social da linguagem e do significado. Londres: Edward Arnold, 1978.

HALLIDAY, M. A. K. Uma Introdução à Gramática Funcional. Londres: Edward Arnold, 1994.

HALLIDAY, M, A, K.; MATTHIESSEN, C. M.I.M. Uma Introdução à Gramática Funcional. 3. ed. London: Edward Arnold, 2004.

HALLIDAY, M. A. K.; MATTHIESSEN, C. M. I. M. Introdução à Gramática Funcional de Halliday. 4. ed. Londres: Routledge, 2014.

LIMA, L. R. Processos existenciais em reportagens de capa da revista Superinteressante. Dissertação (Mestrado em Letras) - Programa de PósGraduação em Letras. Universidade Federal de Santa Maria, Rio Grande do Sul, 2013.

LIMA-LOPES, R. E. Estudos de Transitividade em Língua Portuguesa: O Perfil do Gênero Cartas de Venda. Dissertação (Mestrado em Linguística Aplicada e Estudos da Linguagem) - Programa de Pós-Graduação em Linguística Aplicada e Estudos da Linguagem, Pontifícia Universidade Católica de São Paulo, São Paulo, 2001.

MORAIS, F. B. C. O uso do processo existencial "haver" na escrita acadêmica - um estudo com base em um corpus de artigos científicos de diversas áreas do conhecimento. (Con)textos Linguísticos (UFES), v. 10, n. 14, 2015.

OLIVEIRA, K. F. As orações existenciais em inglês e português brasileiro: um estudo baseado em corpus. Dissertação (Mestrado em Estudos Linguísticos) Programa de Pós-Graduação em Estudos Linguísticos da Faculdade de Letras, Universidade Federal de Minas Gerais, Minas Gerais, 2014.

SCOTT, M. Word Smith Tools versão 7.0. Oxford: Oxford University Press, 2018. 